Jap.Psychol.Research.

No. 2,1955

\title{
ON THE AFTER-EFFECT BY INTERMITTENT PRESENTATION OF INSPECTION FIGURE
}

\author{
NOZAWA, SHIN \\ Department of Psychology, Hokkaido University
}

\section{Problem:}

Ever since the study by Köhler and Wallach (5) was done, the phenomenon of after-effect has attracted the attention of the investigators of perception. These investigators all claim that spatial relation between I.F. and T.F. is the main problem; but the author considers that the rôle of time, such as the observation period for I.F., the time interval between the removal of I.F. and the presentation of T.F. is rather essential than that of space. Although many students obtained more or less similar results from their experiments on the question of time, they have scarcely presented any theory. $(\mathbf{1}, \mathbf{3}, \mathbf{4}, \mathbf{6}, \mathbf{7}, \mathbf{8}, \mathbf{9}, \mathbf{1 0}$.) In these studies the usual procedure has been to present I.F. continuously during the observation period. Now, the aim of this study is to go further investigation of periodical dimension of figural process, by presenting I.F. intermittently, and not continuously ; this approach, the author believes will lead to a new field in the study of after-effect.

\section{Apparatus :}

A dark room was used. A head-rest was installed on a seat for the subject. A large, black screen was placed at the distance of 2 metres in front of the seat in frontal parallel position. On the screen, a sheet of rectangular opal glass was fixed in, at the height of the head-rest. On the surface of the opal glass was pasted a black cardboard on which slits are cut as shown in Fig. I. The central mark $X$ in Fig. I. was meant for the fixation point (F.P.). The line on the right was for normal stimulus (N.S.), and the one on the left, for variable stimulus (V.S.), the length of which, could be adjusted by the experimenter. Behind the screen, two light projectors were set up: one was used for lightening up N.S., and the other for both V.S. and F.P. The brightness of projectors could be adjusted by iris.

Closed to the former projector, an episcotister was placed, so that N.S. could be lighted on and off intermittently, at any rate the experimenter desired.

Procedure-In a dark room, the whole stimuli, N.S., V.S., and F.P. are lighted up all at once. A subject is asked to compare the length of N.S. with that of V.S. while staring at F.P. Then the experimenter begins to lengthen V.S. from the minimum $(5 . \mathrm{cm})$, 
at a constant rate. The subject makes a sign as soon as he recognizes that the varying length of V.S. is just exactly equal to that of N.S. The experimenter turns the light off at once, and records the length V.S. (Test I.). Next, he presents both N.S. and F.P. again, and the subject sees N.S. while fixating his eyes upon F.P. (Inspection period : $40 \mathrm{sec}$.). Inspection period being over, the experimenter, presenting V.S. once again, carries on Test II. in the same way as Test I. Since the effect of inspection period should be known by comparing the result of Test I. with Test II., the author will regard, for the present, the difference between the results of these two as the measure-value of after-effect.

EXPERIMENT A.

basic experiment.

Purpose-This is to examine whether such figural after-effect as Köhler recognized will be produced or not, when the measurement is done by the procedure mentioned above.

Control experiment-To fulfil this aim, control experiment $\mathrm{A}^{\prime}$ and $\mathrm{A}^{\prime \prime}$ were conducted. The procedure for them was almost the same as Exp. A; except that, in case of $A^{\prime}$, all the lights were turned off and no stimuli were presented to the subject through the inspection period; and in Exp. $A^{\prime \prime}$, only $F$. $P$. was presented through this period.

Subject-Nine subjects, consisting of students and members of Psychological laboratory in Hokkaido University were used. They were not told about the present, though they had several experiences of being subjects in the experiments of perception.

Table I.

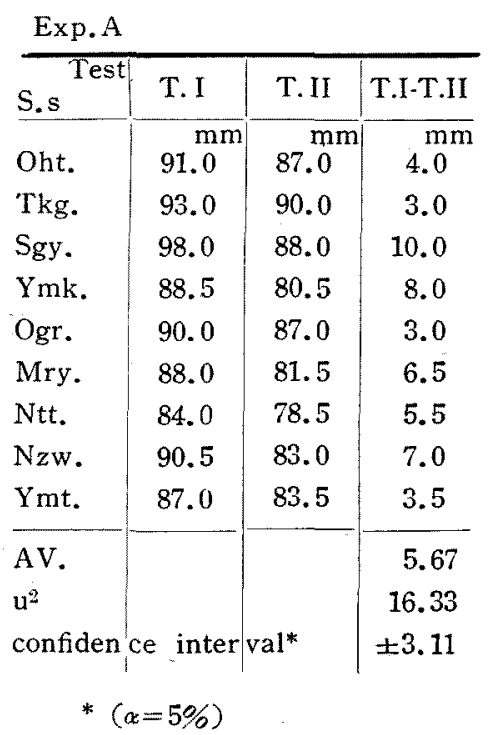

\begin{tabular}{c|r|r} 
Exp. $\mathrm{A}^{\prime}$ & \multicolumn{1}{|c}{} \\
\hline T. I & \multicolumn{1}{|c|}{ T.II } & T.I-T.II \\
\hline $\mathrm{mm}$ & $\mathrm{mm}$ & $\mathrm{mm}$ \\
92.5 & 93.5 & -1.0 \\
96.5 & 95.0 & 1.5 \\
96.0 & 99.0 & -3.0 \\
84.0 & 84.5 & -0.5 \\
86.5 & 88.0 & -1.5 \\
88.0 & 88.0 & 0.0 \\
84.0 & 82.5 & 1.5 \\
88.0 & 87.0 & 1.0 \\
90.0 & 91.5 & -1.5 \\
\hline & & -0.39 \\
& & 2.36 \\
& & \pm 0.40
\end{tabular}

\begin{tabular}{c|r|r} 
Exp. A & \\
\hline T. I & T. II & T.I-T.II \\
\hline $\mathrm{mm}$ & $\mathrm{mm}$ & $\mathrm{mm}$ \\
91.5 & 90.0 & 1.5 \\
96.5 & 95.3 & 1.2 \\
96.0 & 96.0 & 0.0 \\
87.0 & 89.0 & -2.0 \\
87.5 & 88.0 & -0.5 \\
95.0 & 94.5 & 0.5 \\
88.0 & 86.5 & 1.5 \\
89.0 & 92.5 & -3.5 \\
92.0 & 90.0 & 2.0 \\
\hline & & 0.08 \\
& & 3.32 \\
& & \pm 1.41
\end{tabular}

* $(x=5 \%)$ 
The order of the experiment-These experiments, A, $A^{\prime}, A^{\prime \prime}$, and $B$ which will be mentioned later, were conducted in random order with each subject, once or twice a day for two or three consecutive days, during which care was taken to provide each subject with the intermission of an hour at least between one experiment and the next.

Results - Shown in Table I.

(1) In Experiment $A$, the difference between the results of Test I. and II. is statistically significant. (level of significance $\alpha<1 \%$ ).

(2) There is no significant difference between the results of Test I. and II. in either Experiment $\mathrm{A}^{\prime}$ or $\mathrm{A}^{\prime \prime}$.

(3) There is no significant difference among the results of Test $I$. in each experiment.

Discussion-From the result (3), it can be claimed that Test $I$. in each experiment was done almost in the same condition.

The result of $\mathrm{A}^{\prime}$, which will reveal the range of fluctuation caused by repeating a measurement of this kind, indicate that when this test is repeated with the interval of 40 seconds, there is no noticiable change in the apparent length of the the figure.

It can be affirmed also, from the result of $\mathrm{A}^{\prime}$, and the comparison of $\mathrm{A}^{\prime \prime}$ with $\mathrm{A}^{\prime}$, that the observation of F.P. for 40 seconds does rot give any great influence on the succeeding test, Test II. Therefore, the author concludes that the clear difference, shown in the result (1), was produced by $40^{\prime}$ second-observation of N.S. That is to say, the fact, shown in Experiment $A$, is one of the phenomena, named figural after-effect by Köhler.

\section{EXPERIMENT B.}

Purpose - The comparison of the amount of after-effect caused by intermittent presentation of inspection figure with that of continuous presentation.

\begin{tabular}{|c|c|c|}
\hline T. I & T. II & T.I-T.II \\
\hline $\begin{array}{c}\mathrm{mm} \\
93.5\end{array}$ & ${ }_{90.5}^{\mathrm{mm}}$ & $\begin{array}{c}\mathrm{mm} \\
3.0\end{array}$ \\
\hline 95.5 & 89.5 & 6.0 \\
\hline 100.4 & 92.0 & 8.7 \\
\hline 89.5 & 83.0 & 6.5 \\
\hline 93.0 & 86.0 & 7.0 \\
\hline 90.5 & 79.5 & 11.0 \\
\hline 92.0 & 81.0 & 11.0 \\
\hline 93.8 & 81.0 & 12.8 \\
\hline \multirow[t]{2}{*}{91.0} & 80.0 & 11.0 \\
\hline & & $\begin{array}{r}8.63 \\
7.92 \\
\pm 2.87\end{array}$ \\
\hline
\end{tabular}

Procedure-The same as in Experiment $\mathrm{A}$; except that, during the inspection period, only N. S. is to be lighted on and off with the cycle of 1 cps. (F.P. being kept in continuous presentation.)

The subjects are the same with those employed in the preceding experiments.

Results-Shown in Table I.B.

(1) The result of Test I. is not significantly different from those obtained in the preceeding three. 
(2) The difference between Test I. and II. is significant. $(\alpha<1 \%)$.

(3) The amount of after-effect is significantly different from that in Experiment A. The periodical presentation produces greater after-effect than continuous presentation, which is a striking fact.

EXPERIMENT SERIES C AND C'.

Purpose-To see the influence the variation of the length of inspection

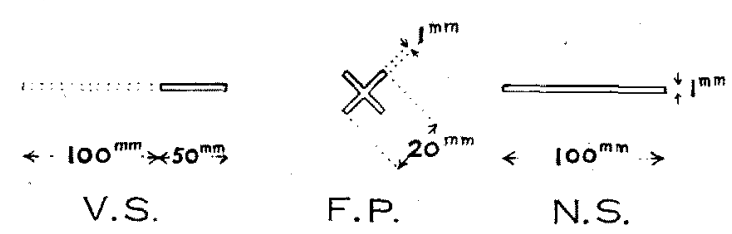

Fig. 1 The Arrangement of the Stmulus FigURES.

period has upon the result, other conditions being kept the same as in Experiment A. and B.

Condition-The one which is correspondent to Experiment $A$ is called Experiment $\mathrm{C}$ series, while the other, correspondent to Experiment $B$, is called Experiment $C^{\prime}$ series (expcet that, the cycle is not 1 cps., but 2 cps.). In Experiment $\mathrm{C}$ series, inspection period was varied among six kinds, as, 15, 30, 60, 120, 150 and 180 seconds. These experiments are called, respectively, $\mathrm{C}_{1}, \mathrm{C}_{2}, \mathrm{C}_{3}$, and so on to $\mathrm{C}_{6}$. Experiment $\mathrm{C}^{\prime}$ series consists of three tests, $\mathrm{C}_{\mathfrak{1}}{ }^{\prime}(20 \mathrm{sec}), \mathrm{C}_{2}{ }^{\prime} \quad(40$ sec.), and $\mathrm{C}_{3}^{\prime}(80$ sec.).

For $C$ series, six subjects were used, and five other subjects, for $\mathrm{C}^{\prime}$ series.
Result-Shown in Fig. 2. The results of both series show that as the inspection period increased, the amount of after-effect also increased.

It is remarkable to see that, in case of $\mathrm{C}$ series, it reached to the maximum within 180 seconds and in case of $\mathrm{C}^{\prime}$ series, it was nearly the maximum within 80 seconds.

According to the usual investigation, the result above mentioned is understood as follows: "Among the usual studies, in case of such investigation as is conducted by the method of adjustment, there can be seen the phenomenon that the longer the in-

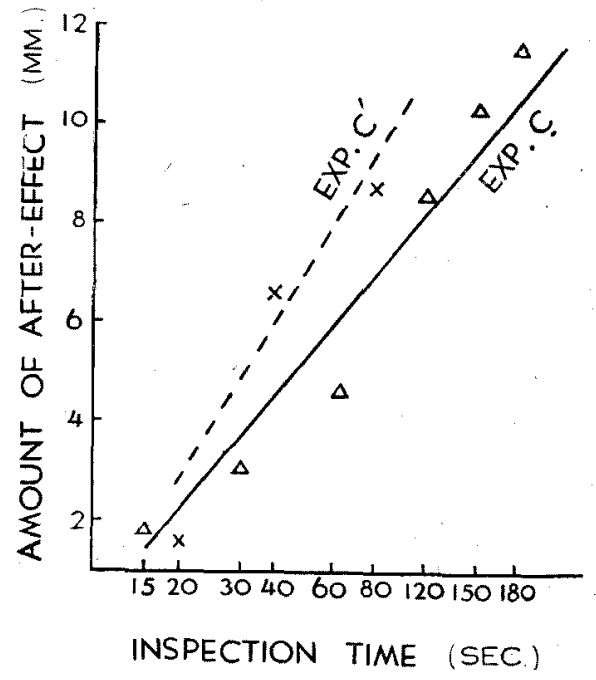

Fig. 2"The Increase of After-effect as A Function of the Doration of Inspector Pertion.

spection period, the more the amount of the after-effect, as the result. However, it is recognized that, when investigated by" the method of complete series which takes less time in mesaur- 
ing the after-effect immediately after the inspection, is nearly constant, in spite of the length of the inspection time; and what, in accordance with the period after the inspection till the end of the measurement, gets longer, the amount of the after-effect rapidly decrease. And also, when the inspection period being short, the rate of decrease of the amount of the after-effect is noticiable."

Consequently, it is proper to reason that the results of $\mathrm{C}$ and $\mathrm{C}^{\prime}$ show the increase of persistency of after-effect with the increase of inspection period. Although the results of $C^{\prime}$ and $C^{\prime}$ should not be compared directly with each other as their conditions are not correspondent, it is not too much to conclude that the after-effect by periodical presetation, when compared with that of continuous presentation, has good deal of persistency.

\section{EXPERIMENT D SERIES,}

Purpose-It was studied wether the cycle of intermittent presentation woult have any effect.

Conditions-The inspection period was set as $40 \mathrm{sec}$. and the cycle of flickering was six kinds, as $1 / 2$ cps. $\left(\operatorname{Exp} . \mathrm{D}_{1}\right), 1 \quad\left(\operatorname{Exp} . \mathrm{D}_{2}\right), 2 \quad\left(\operatorname{Exp} . \mathrm{D}_{3}\right)$, 4 (Exp. $\left.D_{4}\right), 8\left(\operatorname{Exp} . \mathrm{D}_{5}\right)$, and 16 (Exp. $\left.D_{6}\right)$. Six subjects were used.

Results-Shown in Fig. 3.

EXPERIMENT E SERIES.
Purpose-In the experiments mentioned above, presentation and suspension periods of intermittent presentation were always equal. Now, in these

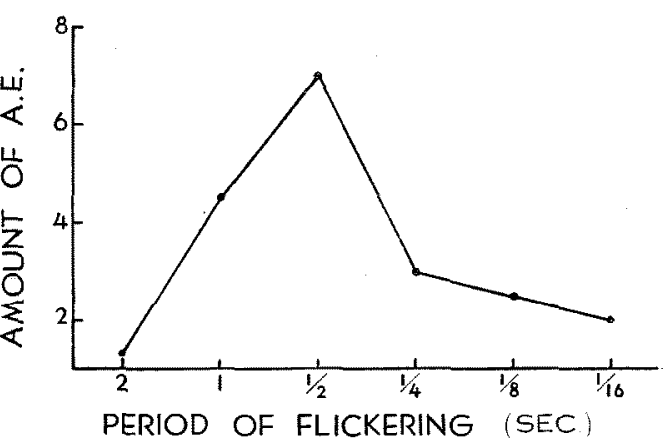

Fig.3 Exp. D. The Increase and Decieas of Afrer-Effict, as a Function on the Period of Flickering.

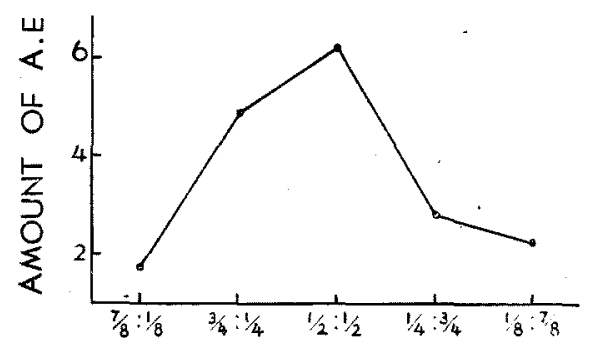

Fis. 4 Exp.E. The Ratio of the Length of Presentation Period to That on Suspension Pertod. (sec.)

series, it was studied what effect would be produced by varying the ratio of the presentation time to the suspension time.

Condition-Inspection period was $40 \mathrm{sec}$. and flickering was one cycle per second. Ratio of presentation period to suspension period was varied among five degrees, as, $7 / 8: 1 / 8\left(\operatorname{Exp} . E_{1}\right), 3 / 4$ $: \mathrm{E}_{1} 1 /{ }_{4}\left(\operatorname{Exp} . \mathrm{E}_{2}\right), 1 / 2: 1 / 2 \quad\left(\operatorname{Exp} . \mathrm{E}_{3}\right)$, $1 / 4:$ E $3 / 4($ Exp. E 4 ), and $1 / 8: 7 / 8$ (Exp. $\left.E_{5}\right)$. Four subjects werer used.

Results;-Shown in Fig. 4. 


\section{EXPERIMENT F SERIES}

Purpose-The results of Experiment $D$ and Experiment $E$ revealed the fact that the effect reached the maximum when the period of flickering was $1 / 2$ second. Now the purpose of this study is to investigate whether the results depend on the $1 / 2$ second presentation, or, on the $1 / 2$ second suspension.

Condition-Taking 40 seconds for the inspection period, the experimenter varied the ratio of presentation to suspension period among these four kinds as follows; $1 / 2$ sec. $1 / \mathrm{s}$ sec. (Exp. $\mathrm{F}_{\mathrm{x}}{ }^{\prime}$ ) $1 / 2: 2$ (Exp. F $2^{\prime}$ ), and $2: 1 / 2\left(E x p . F_{1}{ }^{\prime \prime}\right.$,

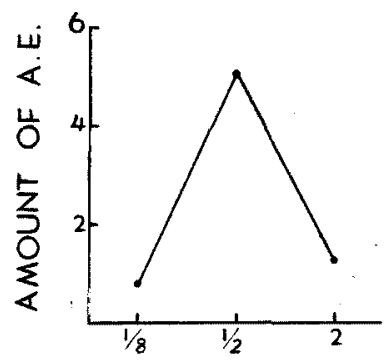

Fig. 5 The Variatron of the Levgth of Suspension Time (sec.) to That of Presentation Time (1/2sec.)

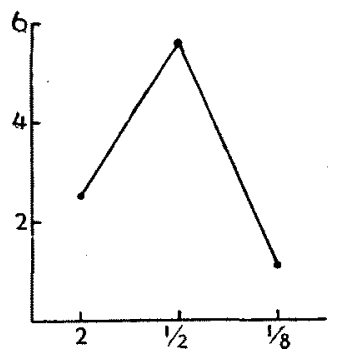

Fifi.6 The Variation of the Length of Presentation Trme (sec.) to That of Suspenston Time (1/2sec.) $1 / 8: 1 / 2\left(\right.$ Exp. $\left.F_{2}{ }^{\prime \prime}\right)$ and; separately, control experiment was done at the ratio of $1 / 2: 1 / 2$ sec. (Exp. F.). Four subjects were used.

Results-Shown in Fig. 5 and 6.

Discussion-The results of Experiment $C^{\prime}$ series show that the amount of after-effect increases as the inspection time increases; we must not forget, though, as we increase the presentation time there results the increase of the total number of flickering as well. However, it is impossible to explain unequivocally the results of Experiment $D$ series and $E$ series, by the factor of either total presentation period or total number of flickering.

That is to say, in Experiment D series, total presentation periods were fixed at 20 seconds, but the amount of after-effect was variable. In Experiment E series, total presentation period of I.F. was varied from $35\left(E_{1}\right)$ to 5 sec. $\left(E_{\overline{0}}\right)$, in decreasing order and aftereffect was the maximum at $1 / 2: 1 / 2$ sec., namely, on condition of Exp. $E_{3}$, the middle one. As for the frequency of flickering, it was fixed at 40 in Exp. $E$ series, and the result was variable; it was varied from 20 to 640 in Exp.D series, and the amount of after-effect was the maximum in $\operatorname{Exp} . D_{3} .(1 / 2: 1 / 2)$

Therefore, no unequivocal relation in these results can be recognized.

Now the author considers that the cycle of flickering in $1 / 2: 1 / 2$ sec. is rather significant. Furthermore, the results of Exp. F series show us that the crucial point here is not $1 / 2 \mathrm{sec}$. 
presentation nor $1 / 2$ sec. suspension considered separately, but the condition of I. F. being lighted on and off at the cycle of $1 / 2$ second.

It has been found that the flickering of $1 / 10 \mathrm{sec}$. period make the phenomenal brightness of the stimulus figure the maximum (2); so it might be argued that the result, such as of Exp. B., has been produced by the change of the phenomenal brightness of the figure. However, this hypothesis would not be tenable.

Table. 2

\begin{tabular}{r|r|r|r} 
& \multicolumn{3}{|c}{ Exp. G' } \\
\hline SS. Test & \multicolumn{1}{|c|}{ T.I } & \multicolumn{1}{|c}{ T.II } & T.I-T.II \\
\hline Tkd. & 103.5 & 100.5 & 2.0 \\
Sit. & 100.2 & 93.0 & 7.2 \\
Tvn. & 92.0 & 85.5 & 6.5 \\
Mvy. & 100.0 & 98.5 & 1.5 \\
Ymt. & 95.0 & 93.5 & 1.5 \\
Nzw. & 100.5 & 99.0 & 1.5 \\
AV. & 98.5 & 95.2 & 3.4 \\
\hline$u^{2}$ & & & 0.7
\end{tabular}

In spite of the fact that the subjects saw the I.F. of Exp. $D_{5}$ apparently brighter than that of any other condition, there was not much 'amount of after-effect.

\section{EXPERIMENT G.}

Purpose-In the experiments above, flickering of stimulus was carried out most regularly. Here, in Experiment G., the result of flickering N.S. irregularly was compared with that of regular one.
Condition-N. S. was lighted on and off during the inspection period by using an episcotister which varied the presentation period and suspension period among $2,1,1 / 2,1 / 4$, and $1 / 8$ second in quite a random order. As the control experiment, Experiment G, in which N.S. was presented continuously for $40 \mathrm{sec}$., was conducted with the same subjects as those in Experiment G.

Result-Shown in Table 2. There is no significant difference between the

\begin{tabular}{r|r|r}
\multicolumn{3}{c|}{ Exp.G } \\
\hline T.I & \multicolumn{1}{c|}{ T.II } & T.I-TII \\
\hline $\mathrm{mm}$ & $\mathrm{mm}$ & $\mathrm{mm}$ \\
106.5 & 104.5 & 2.0 \\
96.5 & 89.5 & 7.0 \\
94.0 & 90.5 & 3.5 \\
98.0 & 94.0 & 4.0 \\
93.8 & 90.5 & 3.3 \\
102.5 & 97.0 & 5.5 \\
98.6 & 94.3 & 4.2 \\
\hline & & 0.3 \\
& &
\end{tabular}

results of Experiment $G$ and $G^{\prime}$.

SUMMARY AND CONCLUSIONS

(1) When straight line of stimulus figure is under prolonged inspection, its phenomenal length decreases. This is one kinds of figural after-effect.

(2) After-effect can be produced by means of intermittent presentation of I. F., instead of continuous presentation; and more amount of after-effect appears on some condition, in intermittent presentation rather than in 
continuous presentation.

(3) In case of intermittent presentation, other condition being the same, the longer the total presentation period, the more amount of after-effect.

(4) If the cycle of flickering in intermittent presentation are varied, the after-effect becomes the maximum when presentation and suspension periods are both within $1 / 2$ second.

(5) In interimittent presentation, irregular flickering does not particularly affect the amount of after-effect.

In these results, the author believes, especially (2) and (4) are not only the new facts, but also, are very important for the theory construction of figural after-effect. However, this study still remains a preliminary exploring one, the control of conditions of each experimental series is not yet satisfactory, so that it is absolutely necessary to go into further investigation by more systematic method wiht more appropriate condition.

\section{REFERENCE}

1) Bales, J. F. and Follansbee, G. L. :
The after-effects of the perception of curved lines. J.Exp. Psychol. Vol.18 (1934) 499-503.

2) Bartley, S.H. : Some factors in bright. ness discrimination. Psychol. Rev. Vol. 4.6 (1939) $337-358$.

3) Gibson, J. J. and Radver, M. : Adaptation, after-effect and contrast in the perception of tilted lines. J.Exp.Psychol. Vol. 20 (1937) 453-467.

4) Hammer, E. R. : Temporal factors in figural after-effects. Amer. J. Psychol. Vol.62 (1949) 337-354.

5) Köhler, W. and Wallach, H. : Figural after-effect; an investigation of visual process. Proc. Amer. Phil. Sci. Vol. 88 (1944) 299-357.

6) Mueller, C. G. : Numerical transformation in the analysis of experimental data. Psychol Bull. Vol. 46 (1949)198223.

7) Nozawa, S. : Prolonged inspection of a figure and the after-effect there of. Jap.J.Psychol. Vol. 24 (1953) 47-58.

8) Obonai, T. and Ikeda, H. : The Quantitative analysis of figural afte-effects. I. -The process of growth and decay of figural after-effects-Jap.J. Psychol. Vol. 23 (1953) 246-260.

9) Oyama, T. : Experimental studies of figural after-effects: (1) Temporal factors. Jap.J. Psychol. Vol.23 (1953) 239245.

10) Shibuya, K.: The quantitative analysis of the process of decay of figural after-effects and after images (abstract only) Jap.J.Psychol. Vol. 22 (1952) 248. 